\title{
Changes in diversity, biomass and abundance of soil macrofauna, Parrotio-Carpinetum forest at organic and semi-organic horizons
}

\author{
Masomeh Izadi *, Hashem Habashi
}

Gorgan Agricultural Sciences and Natural Resources University, Faculty of Forest Science, Gorgan, Iran

\begin{abstract}
Present study evaluates diversity, abundance and biomass of soil macrofauna in organic and semi-organic horizons in Parrotia persica-Carpinus betulus forest in Shast kola area. Totally 70 sample points were randomly selected from organic and semiorganic horizons then sampling was done by a rectangle $100 \mathrm{~cm}^{2}$ area. Soil macrofauna were separated from soil samples by hand sorting and using Berlese funnel then dried at $60^{\circ} \mathrm{C}$ for $72 \mathrm{~h}$ and weighted in 0.001 gr. With using taxonomic classification key, thirteen macrofauna orders were identified. Most of abundance of soil macrofauna in both soil horizons were allocated to Millipedes order. Changes in diversity, abundance and biomass of macrofauna in both soil horizons were calculated. The results showed Shannon diversity index, Simpson evenness and Margalef richness indices in semiorganic horizon were more than organic horizon. Abundance and biomass of macrofauna in semi-organic horizon were more than organic horizon.
\end{abstract}

Received : 28.09 .2015

Accepted : 08.01.2016

Keywords: Macrofauna, shannon diversity, simpson evenness, Margalef richness, biomass

(C) 2016 Federation of Eurasian Soil Science Societies. All rights reserved

\section{Introduction}

Biodiversity is described as whole plant, animals and microorganisms species which are associated with ecosystems (Altieri, 1999). Soil is one of the most diverse and important habitats in the earth having species richness and includes one of the best combination of living organisms with highest diversity (Khodashenas et al. 2012). Soil fauna have great diversity and according to recent estimates, soil organism might exhibit more than 23 percent of whole living animal's diversity which are defined until now. In some ecosystems, local variation of soil fauns could be very great which could be greatly more than plants and animals group on the earth (Lavelle et al. 2006). Diversity and abundance of soil fauna was used as tension index for soil (Palacios-Vargas et al. 2007). Having regard to importance of invertebrates in litter decomposition and nutrients cycle, invertebrates' diversity is the index which shows the area current status and could be used as the best factor in determination of soil quality (Moghimian and Kooch, 2013). Extreme decrease of soil biodiversity, especially loss of species with unique functioning could have digastric affect which results in long-term soil degradation and loosing agricultural products capacity (Ruiz et al. 2008). Soil fauna are of the main components of ecosystem because they have critical role in accelerating decomposition of organic

\footnotetext{
${ }^{*}$ Corresponding author.

Gorgan Agricultural Sciences and Natural Resources University, Faculty of Forest Science, Gorgan, Iran

Tel.: +989119529116

E-mail address: m.izadi460@yahoo.com

e-ISSN: 2147-4249 
matters and transferring nutrients, though decomposition is the result of microbial activity of soil fauna (fungi and bacteria) (Xin et al. 2012).

Soil fauna affect decomposition process both directly by fragmentation of litter organic matter and indirectly by changing microbial function (Lavelle et al. 2006). Most of soil fauna are existed in top $30 \mathrm{~cm}$ of soil surface, although some of them are in lower depth of soil. When soil surface conditions are unfavorable, soil fauna move to lower layers of soil. Most of soil fauna existed in surface layers since these layers includes most of nutrients (Ruiz et al. 2008). Protection of soil macrofauna could help maintenance of earth, because these fauna support nutrients cycle and decomposition processes as well as modification of soil physical properties (Mathieu et al. 2005). Determination of diversity, richness and abundance indices of fauna are required in ecology and habitat management and conservation programs and ecosystem evaluation (Nahmani et al. 2005). These indices are very useful in quantification of soil macrofauna biodiversity pattern (Gonglanski et al. 2008). The objective of this study was to compare the indices of Shannon diversity, Simpson evenness and Margalef richness as well as abundance and biomass of macrofauna in two organic and semi-organic soil horizons in Shast-Kalate forest of Gorgan.

\section{Material and Methods}

\section{Study Area}

This study was carried out in compartments 7, 8, 15, and 17, district 1 of Shast-Klateh (Bahram Nia) Forest, Experimental and Educational Forest of Gorgan University of Agriculture Sciences and Natural Resources. It is located in northen Iran between $36^{\circ} 45^{\prime}$ and $36^{\circ} 46^{\prime} \mathrm{N}$ latitude and $54^{\circ} 24^{\prime}$ and $54^{\circ} 21^{\prime} \mathrm{E}$ altitude. Annual precipitation was $649 \mathrm{~mm}$ and elevation in studied parcels varied between 300 and $630 \mathrm{~m}$ a.s.l. Dominant forest type of these parcels are Parrotia persica-Carpinus betulus.

\section{Data Collection Method}

In order to determination of diversity and abundance of soil macrofauna, 70 sample points randomly selected from organic and semi-organic horizons. The sampling container was rectangle a $100 \mathrm{~cm}^{2}$ area. Samples were placed in plastic bags and immediately transferred to laboratory and soil macrofauna were separated manually and using Berlese funnel. Samples were stored in plastic repository with $75 \%$ ethanol for next steps (Palacios-Vargas, 2007). Soil macrofauna were identified using taxonomic classification keys up to order level (Borror et al. 1989; Ruiz et al. 2008). Macrofauna biomass was calculated after oven-dried at $60^{\circ} \mathrm{C}$ for $72 \mathrm{~h}$ and weighing in $0.001 \mathrm{gr}$ (Rahmani and Mayvan, 2004).

\section{Data analysis}

Calculation of Shannon diversity index, Simpson uniformity index and Margalef richness index. There are various ways of measuring diversity of soil fauna. In current research, the formulas of Shannon - Wiener (diversity), Simpson (evenness) and Margalef (richness) indices were used as follows (Mbuthia et al., 2012).

1.Shannon - Wiener diversity index.

$$
H=-\sum_{i=1}^{s}\left(P_{i}, \operatorname{Ln} P_{i}\right)
$$

Where $\mathrm{H}^{\prime}$ is Shannon - Wiener index; $\mathrm{S}$ is invertebrate's group's number; Pi is average abundance of per invertebrates groups; Ln is natural logarithm.

2.Simpson evenness (heterogeneity) index.

$$
D=\sum_{i=1}^{s} P_{i}^{2}
$$

Where, D is Simpson evenness index; S is invertebrate's group's number; Pi is average abundance of per invertebrates groups

3.Margalef richness index.

$$
R=\frac{s-1}{\ln N}
$$

Where $\mathrm{R}$ is Margalef richness index; $\mathrm{S}$ is invertebrate's group's number; In is natural logarithm; $\mathrm{N}$ is number of populations. 
In order to study the diversity indices of soil macrofauna between two horizons, PAST software was used and then resulted data processed by SPSS v.16 software. Initially, normal being of data assessed using Kolemogroph Smirnof test and if data were not normal, normalized using different methods such as Log 10. For comparing changes in biomass and diversity of macrofauna at two organic and semi-organic horizons tpair test and for comparing changes in abundance at both horizons, non-parametrical Wilcoxon test was used.

\section{Results and Discussion}

At 70 collected samples from organic horizon surface to end of semi-organic horizon, 13 macrofauna order were recognized which include Diplopoda, Isopoda, Hymenoptera, Diptera larvae, spiders, Chilopoda, Coleoptera, Haplotuxidae (earthworm Order), Opilionida, Heteroptera, Amphipoda, lepidoptera larvae and stylommatophora snails. Total abeundance of soil macrofauna at two sampling horizon were 10000000 number per ha which Diplopodas by 3557143 number per ha was the most abeundant (Figure 1). Total biomass amount at both horizons was $141.11 \mathrm{~kg} / \mathrm{ha}$ which greatest amount was associated to mollusks by $64.42 \mathrm{~kg} / \mathrm{ha}$ (Figure 2). In organic horizon total fauna abundance was 3958714 per ha which the greatest amount was related to Diplopodas and total biomass amount at this horizon was $58.5 \mathrm{~kg}$ which the greatest biomass was related to snails (Figure 1). In semi-organic horizon total macrofauna abundance was 6014286 per ha which the greatest amount was related to Diplopodas (Figure 1) and total biomass amount at this horizon was $82.62 \mathrm{~kg}$ which the greatest biomass was related to snails (Figure 2).

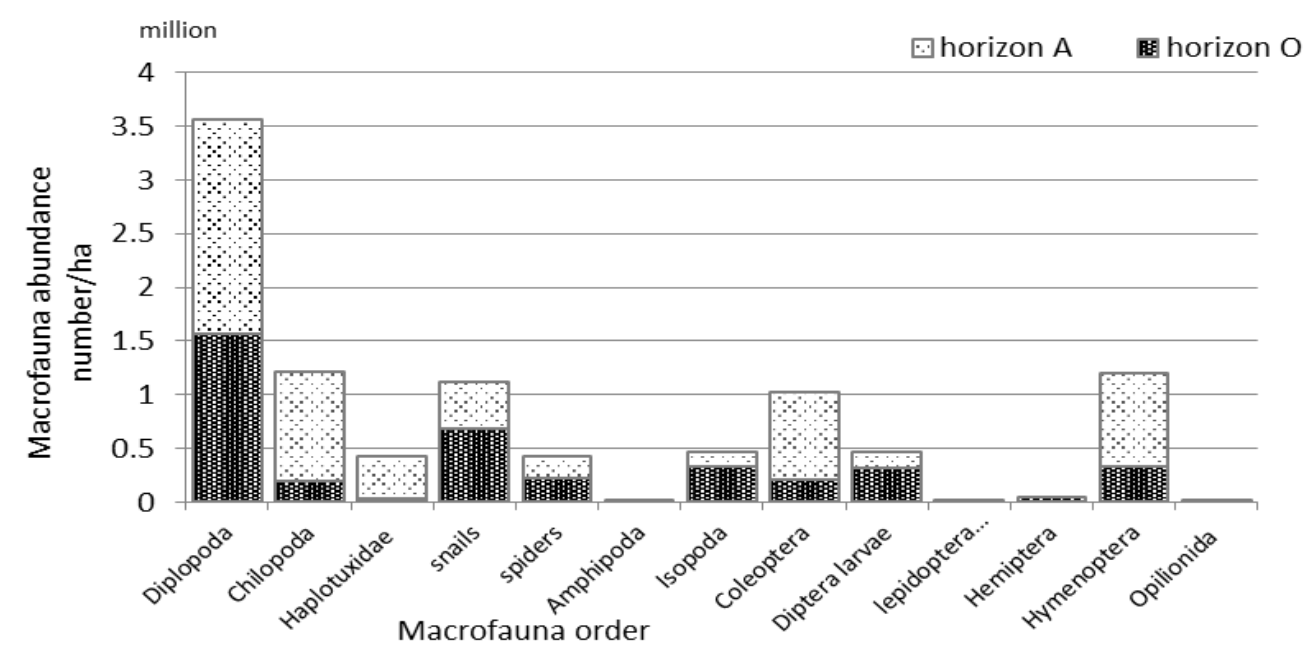

Figure 1. Macrofauna abundance at organic and semi-organic horizons

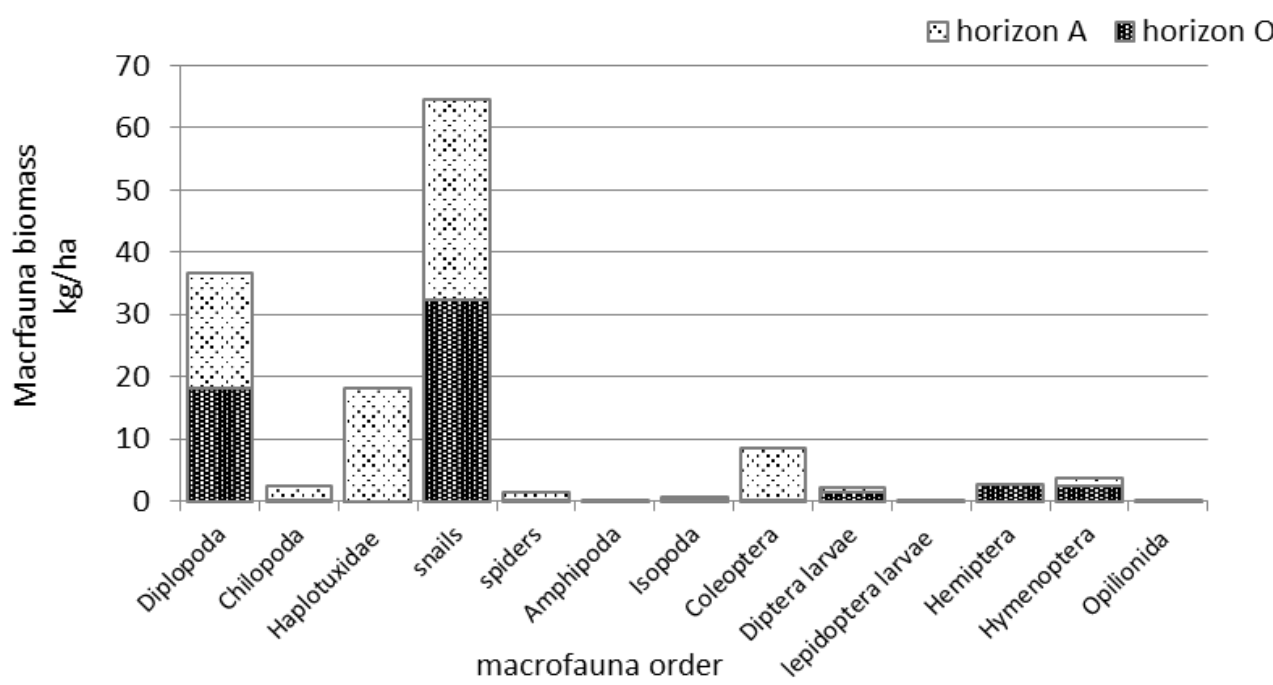

Figure 2. Macrofauna biomass at organic and semi-organic horizons.

Results from paired t-test stated that there is significant difference between numerical amount of Shannon index at two organic and mineral horizon at 99\% probability level. So, Shannon index amount in semiorganic horizon was greater than organic horizon (Figure 3). Also, results of numerical amount of Simpson 
evenness index in both horizons showed significant differences which greatest amount was related to semiorganic horizon (Figure 3). Comparisons of Margalef richness index mean of showed significantly differences which the greatest amount was related to semi-organic horizon (Figure 3). Also macrofauna biomass in both depths showed significantly differences that the greatest amounts were allocated to semi-organic horizon (Figure 4).

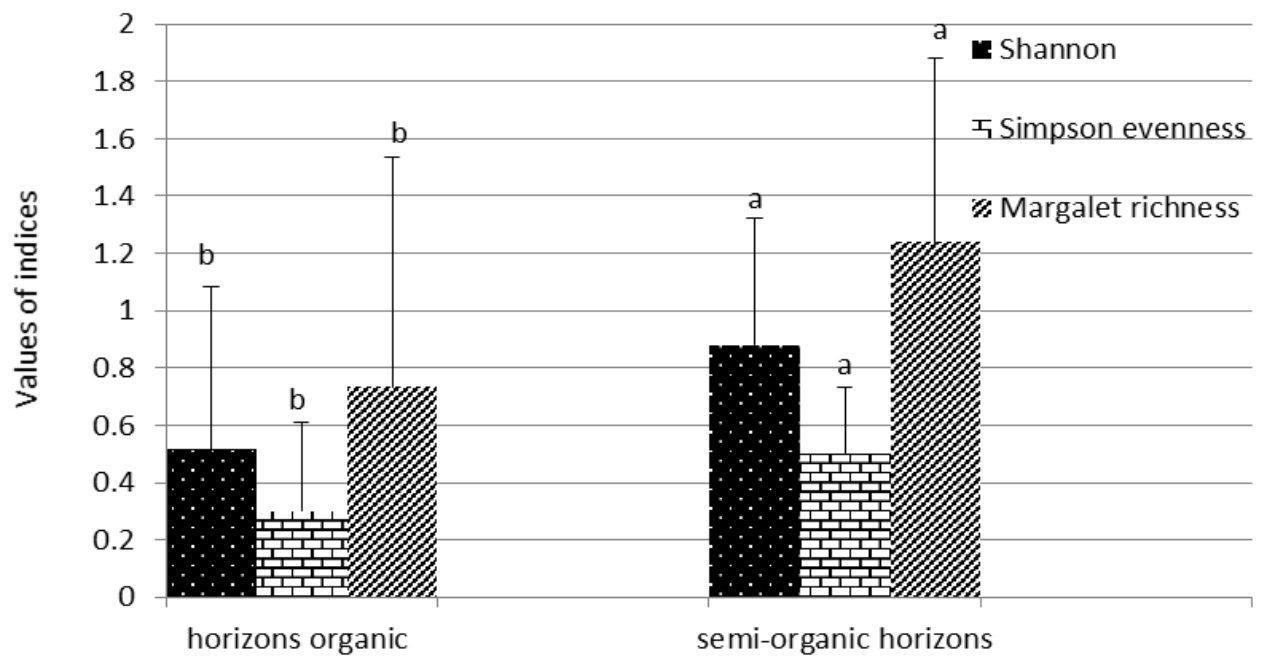

Figure 3. Average amount of Shannon diversity, Simpson evenness and Margalef richness indices at organic and semiorganic horizons.

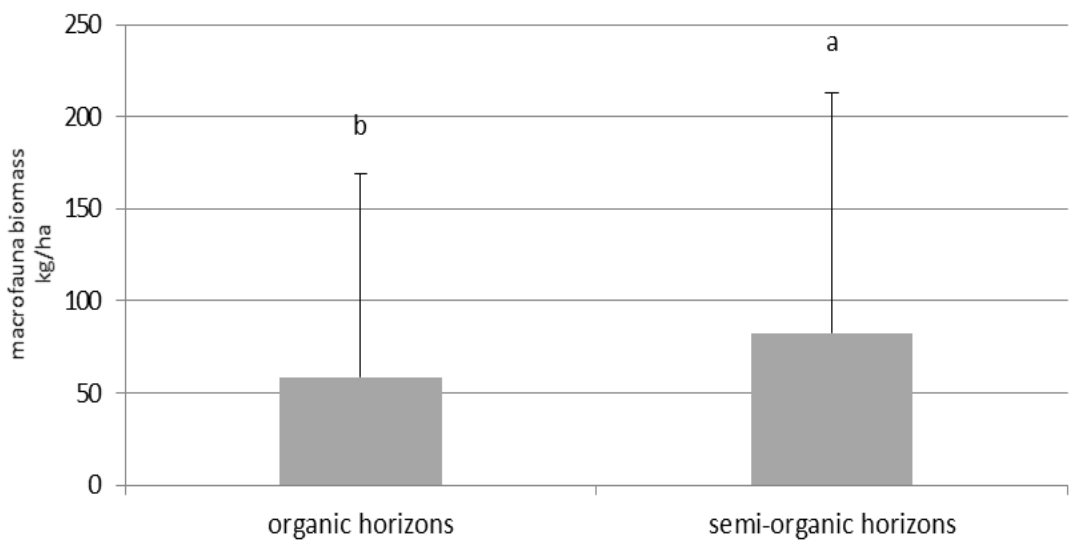

Figure 4. Average amount of macrofauna biomass at organic and semi-organic horizons.

The results of Mann-Whitney $U$ test showed that there was significant difference between macrofauna abundance in two organic and semi-organic horizons while the greatest amount belong to semi-organic horizon (Figure 5).

In the studied area, Diplopoda order has great abundance. Hassall et al. (1987) and David and Handa (2010) stated that Isopoda and Diplopoda are most frequent macrofauna in temperate forests and have considerable contribution in decomposing litter and nitrogen content.

Vegetation cover not only supply considerable fraction of soil organic matter, but indirectly determines soil fauna composition (Frouz et al. 2006). Rahmani and Mohammadnejad Kiasari (2003) noted that tree species is the most important factor in increasing Diplopoda Population. Also, Loranger et al. (2003) stated that Diplopoda due to presence of foliage of Pisonia subcordata enriched by nitrogen at secondary estuary and semi-estuary forests has great abundance. Amini et al. (2011) obtained Carpinus betulus nitrogen amount as 1.69 \% indicating nitrogen richness of Carpinus betulus litter. Warren and Zou (2002) stated that biomass of Diplopoda Class has greatest association with nitrogen concentration and $\mathrm{C} / \mathrm{N}$ ratio at litter layer $\mathrm{O}_{\mathrm{i}}$. having regard to this point that vegetation type of studied area in terms of volume is Carpinus betulus -Parrotia persica, which Carpinus betulus share is $58.27 \%$ of volume and $32.75 \%$ of mass abundance, therefore it can be concluded that increasing in litter nitrogen amount caused attraction of Diplopoda. 


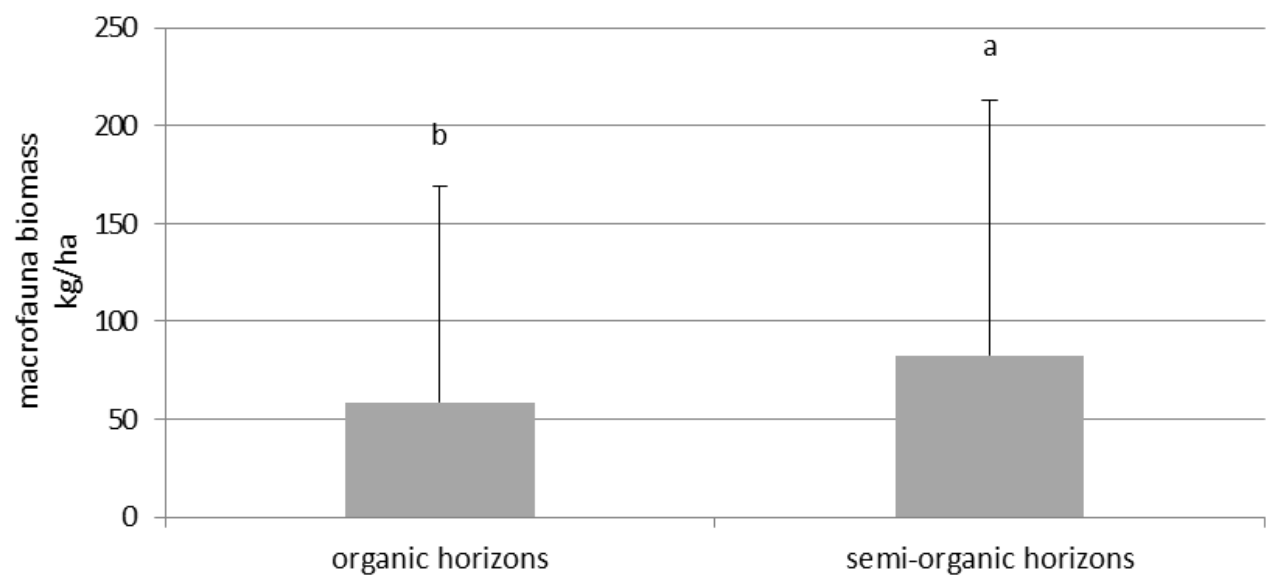

Figure 5. Average amount of macrofauna abundance at organic and semi-organic horizons.

Diversity, evenness and richness indices of macrofauna were calculated by Shannon, Simpson and Margalef equation for both organic and semi-organic soil horizons. Shannon diversity, Simpson evenness and Margalef richness indices amounts in both depths indicated specific pattern. Shannon diversity, Simpson evenness and Margalef richness indices are highest in semi-organic horizon and showed significantly difference with organic horizon (Figure 3). Rahmani and Mayvan (2004) stated that diversity indices in decayed organic layers is more than undecayed organic layers and highest diversity index amount is allocated to decayed organic layer and lowest amount is associated to 20-30 cm layers. Moghimian et al. (2013) stated that all of diversity indices except Margalef richness index have significant difference in 0-10 and $10-20 \mathrm{~cm}$ introducing organic materials into soil through plant residues affects moisture and temperature of soil invertebrates. Presence of plant residues in soil surface, in addition to supplying soil invertebrates nutrition, caused microclimates changes, since reduces sunlight receiving at soil surface and decrease soil temperature and indirectly will increase soil moisture content which is favorable for growth and development of soil invertebrates. On the other hand, accumulation of soil organic matter results in increasing soil moisture holding capacity and affects soil invertebrates association (Sileshi and Mafongoya, 2006). Considering to that semi organic horizon composed of un-decayed organic matters which don't consumed by macro organisms and/or a little amount is consumed, therefor it can be said that this horizon plays habitat and nest role for soil macrofauna.

It is previously determined that organic matter content and quality, quantity and depth of forest floor affects Colembola spatial distribution (Hasegawa, 2010). Having regard to this point that evenness and richness caused increasing diversity, present study shows that evenness and richness indices amount at semi organic horizon was highest amount which results in greatest amount of diversity index (Figure 3).

Studying the abundance and biomass of soil macrofauna showed that amounts in semi-organic horizon were more than organic horizon and showed significant difference (Figure 4). Irannejad and Rahmani (2009) stated that 82 to $86 \%$ of number and biomass of earthworms are presented in 0 to $10 \mathrm{~cm}$ layer.

\section{Conclusion}

In the present study, the greatest soil macrofauna abundance was related to Diplopoda order. Species vegetation litter type includes Carpinus betulu and Parrotia persica caused attraction of Diplopodas. Also, the maximum value of Shannon diversity, Simpson evenness and Margalef richness indices among two organic and semi organic horizons, was assigned to semi-organic horizon. The most abundance macrofauna biomass was observed in semi-organic horizon which could be due to composition and depth of organic matter content.

\section{References}

Altieri, M.A., 1999. The ecological role of biodiversity in agroecosystems. Agriculture, Ecosystems and Environment 74(13): $19-31$. 
Amini, R., Rahmani, R., Habashi, H., 2011. Nitrogen, phosphorus and carbon dynamics of hornbeam leaf litter (Case study: District one, Shastkalate forest, Gorgan). Iranian Journal of Forest and Poplar Research 19(1): 94-103.

Borror, D. J., Triplehorn, C.A., Johnson, N.F., 1989. An introduction to study of insect. Saunders Collage Publishing Co., Philadelphia, $864 \mathrm{p}$.

David, J.F., Handa, I.T., 2010. The ecology of saprophagous macroarthropods (millipedes, woodlice) in the context of global change. Biological reviews of the Cambridge Philosophical Society 85(4): 881-895.

Frouz, J., Elhottová, D., Kuráž, V., Šourková, M., 2006. Effects of soil macrofauna on other soil biota and soil formation in reclaimed and unreclaimed post mining sites: Results of a field microcosm experiment. Applied Soil Ecology 33(3):308-320.

Gonglanski, K.B., Gorshkova, I.A., Karpov, A,I., Pokarzhevskii, A.D., 2008. Do boundaries of soil animal and plant communities coincide? A case study of a Mediterrranean forest in Russia. European Journal of Soil Biology 44(4):355-363.

Hasegawa, M., 2001. The relationship between the organic mather composition of a forest floor and the structure of a soil arthropod community. European Journal of Soil Boilogy 37(4): 281-284.

Hassall, M., Turner, J.G., Rands, M.R.W., 1987. Effects of terrestrial isopods on the decompostion of woodland leaf litter. Oecologia 72(4): 597-604.

Irannejad, E., Rahmani, R., 2009. Evaluation of earthworm abundance and vertical distribution prttern in some forest types of ShastKolateh. Journal of Forest and Wood Products 62(2): 145- 157.

Khodashenas, A., Koocheki, A., Rezvani Moghaddam, P., Lakzian, A., 2012. Evaluation of structural biodiversity in natural systems of arid and semiarid regions: 1- Soil characteristic and biodiversity. Journal of Natural Environment 65(2): 165-173.

Lavelle, P., Decaëns, T., Aubert, M., Barot, S., Blouin, M., Bureau, F., Margerie, P., Mora, P., Rossi, J.-P., 2006. Soil invertebrates and ecosystem services. European Journal of Soil Biology 42(S1): S3-S15.

Loranger, G., Ponge, J.F., Lavelle, P., 2003. Humus forms in two secondary semi-evergreen tropical forests. European Journal of Soil Science 54(1): 17-24.

Mathieu, J., Rossi, J.-P., Mora, P., Lavelle, P., da S. Martins, P. F., Rouland, C., Grimaldi, M., 2005. Recovery of Soil Macrofauna Communities after Forest Clearance in Eastern Amazonia, Brazil. Conservation Biology 19(5): 15981605.

Mbuthia, E.W., Shariff, J.H., Raman, A., Hodgkins, D.S., Nicol, H.I., 2012. Abundance and diversity of soil arthropods and fungi in shelterbelts integrated with pastures in the central tablelands of New South Wales, Australia. Journal of Forest Science 58(12): 560-568.

Moghimian, N., kooch, Y., 2013. The effect some of physiographic factor and soil physic- chemical features of Hornbeam forest ecosystem on earthworm biomass. Journal of wood and Forest Science and Technology 20(2): 1-21.

Nahmani, J., Capowiez, Y., Lavelle, P., 2005. Effects of mental pollution on soil macro invertebrate burrow systems. Biology and Fertility of Soils 42: 31-39.

Palacios-Vargas, J.G., Gastano-Meneses, G., Gomez-Anaya, J.A., Martinez-Yrizor, A., Mejia- Recamier, B.E., Martinezsanchez, J., 2007. Litter and soil arthropods diversity and density in atropical dry forest ecosystem in western Mexico. Bodiversity and Conservation 16(3): 3703-3717.

Rahmani, R., Mayvan H.Z., 2004. Diversity and assemblage structure of soil invertebrates in Beech, hornbeam and Oakhornbeam forest type. Iranian Journal of Natural Resources 56(4): 425-436.

Rahmani, R., Sh, Mohammadnejad Kiasari., 2003. Relation Between Millipedes Abundance and Litter Nutritional Elements Composition in Afforested and Disturbed Sites (Case Study: Darabkola-Mazandaran). Iranian Journal of Natural Resources 56(3): 201-213.

Ruiz, N., Lavelle, P., Jimenez, J., 2008. Soil Macrofauna field manual: Technical Level. Food and Agriculture Organization of The United Nations (FAO). Rome, Italy. 100p.

Sileshi, G., Mafongoya, P.L., 2006. Long-term effects of improved legume fallows on soil invertebrate macrofauna and maize yield in eastern Zambia. Agriculture Ecosystems \& Environment 115(1-4): 69-78.

Warren, M.W., Zou, X., 2002. Soil Macrofanua and Litter Nutrients in three tropical tree plantation on a disturbed site in puerto Rico. Forset Ecology and Management 170(1-3): 161-171.

Xin, W.D., Yin, X.Q., Song, B., 2012. Contribution of soil fauna to litter decompsition in Songnen sandy lands in northeastern China . Journal of Arid Environments 77: 90-95. 